\title{
DEVELOPMENT OF APPROACHES TO EVALUATING THE INVESTMENT ATTRACTIVENESS OF THE COMPANY
}

\author{
Prof. DSc. Alena Stupina ${ }^{1,2}$
}

Assoc. Prof. Roman Kuzmich ${ }^{1}$

Assoc. Prof. Margarita Karaseva ${ }^{1,2}$

Assoc. Prof. Irina Bagdasarian ${ }^{1}$

\section{Bh. Student Artem Stupin ${ }^{2}$}

${ }^{1}$ Siberian Federal University, Russia

${ }^{2}$ Reshetnev Siberian State University of Science and Technology, Russia

\begin{abstract}
In most cases, it is difficult for an investor to make a choice of a particular enterprise for the investment due to the uncertainty of business development in a constantly changing market economy. It is recommended to invest in companies with a good reputation, since such investments are less risky in conditions of uncertainty. First of all they try to invest in companies that meet the basic needs of customers such as trade, food production, and construction.
\end{abstract}

The main problem for an investor in decision making concerning money investment in a company is a correct evaluation of its investment attractiveness. The paper presents and approves two approaches to evaluating the investment attractiveness of a company to solve this problem. It allows an investor to make a choice in favor of those companies in which it is profitable to invest. A comparison of the results of the proposed approaches is given. A number of construction companies from Krasnoyarsk, a large industrial center in Central and Eastern Siberia, are used as a research object. The choice of the studied object is due to the rapid development of the construction industry in Krasnoyarsk.

Note also that these approaches to evaluating investment attractiveness can be used for smaller companies and other manufacturing industries.

Keywords: investment attractiveness, business value, financial transparency, construction companies. 